\title{
Interstitial Pregnancy Resulting in a Viable Infant Coexistent with Massive Perivillous Fibrin Deposition: A Case Report and Literature Review
}

\author{
Yusuke Tanaka, MD ${ }^{1}$ Kazuya Mimura, MD ${ }^{1}$ Takeshi Kanagawa, $\mathrm{MD}^{1}$ Masahiro Nakayama, MD, $\mathrm{PhD}^{2}$ \\ Shinya Matsuzaki, MD, $\mathrm{PhD}^{1} \quad$ Yukiko Kinugasa-Taniguchi, MD, $\mathrm{PhD}^{1}$ Masayuki Endo, MD, $\mathrm{PhD}^{1}$ \\ Tadashi Kimura, MD, $\mathrm{PhD}^{1}$
}
${ }^{1}$ Department of Obstetrics and Gynecology, Osaka University Graduate School of Medicine, Suita, Osaka, Japan
2 Department of Pathology and Laboratory Medicine, Osaka Medical Center and Research Institute for Maternal and Child Health, Izumi, Osaka, Japan

\begin{abstract}
Address for correspondence Kazuya Mimura, MD, Department of Obstetrics and Gynecology, Osaka University Graduate School of Medicine, 2-2 Yamadaoka, Suita, Osaka 565-0871, Japan

(e-mail: kazuya.med_ob-gyne@hotmail.co.jp).
\end{abstract}

Am J Perinatol Rep 2014;4:29-32.

\begin{abstract}
Keywords

- ectopic pregnancy

- fetal growth restriction

- interstitial pregnancy

- massive perivillous fibrin deposition

- placenta accreta

Objective The objective of this report is to describe a rare case of interstitial pregnancy ultimately resulting in a viable infant coexistent with massive perivillous fibrin deposition (MPFD).

Study Design This study is a case report and literature review.

Results A 35-year-old female patient underwent cesarean section at 32 weeks of gestation due to fetal growth restriction (FGR) and breech presentation. During the operation, a diagnosis of interstitial pregnancy was established. There was no evidence of placental separation. We decided to complete surgery without removal of the placenta and waited until the placenta delivered spontaneously. The conservative management was successful, and the patient was discharged on postoperative day 13. The pathologic examination showed MPFD.

Conclusion If interstitial pregnancies are not diagnosed at an early gestational age, it can result in a viable fetus, but such pregnancies may be associated with FGR or placenta accreta.
\end{abstract}

Interstitial pregnancies account for approximately $2 \%$ of all ectopic pregnancies. ${ }^{1}$ Rupture of an interstitial pregnancy can lead to life-threatening hemorrhage. The interstitial part of the fallopian tube is the proximal portion of the tube that is within the muscular wall of the uterus. Because of the increased distensibility of this portion, an interstitial pregnancy may remain asymptomatic and unruptured until 14 to 16 weeks of gestation. ${ }^{1}$ We herein report an extremely rare case of an unruptured interstitial pregnancy with a live birth.

\section{Case Report}

A 35-year-old primiparous female patient without any history of infertility or previous uterine surgery conceived spon- taneously. She was transferred to our hospital from her private clinic for management of suspected fetal growth restriction (FGR) at 31 weeks of gestation. Physical and laboratory examination showed that there were no findings of hypertension or preeclampsia. An ultrasound examination noted the fetus in the breech presentation. Umbilical artery Doppler ultrasound examinations showed reversed end-diastolic velocity and contraction stress test was positive. After the patient received antenatal corticosteroids (betamethasone $12 \mathrm{mg}$ every 24 hours for two doses), cesarean section was performed at 32 weeks of gestation due to breech presentation. A male neonate weighting 1,038 g (-3.0 SD) was delivered with Apgar scores of 7 and 9 at 1 and 5 minutes, respectively. At the time of surgery, the uterine fundus on the received

October 30, 2013

accepted after revision

December 23, 2013

published online

March 12, 2014
DOI http://dx.doi.org/

10.1055/s-0034-1370354. ISSN 2157-6998.
Copyright $\odot 2014$ by Thieme Medical Publishers, Inc., 333 Seventh Avenue, New York, NY 10001, USA. Tel: +1(212) 584-4662.
License terms

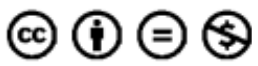




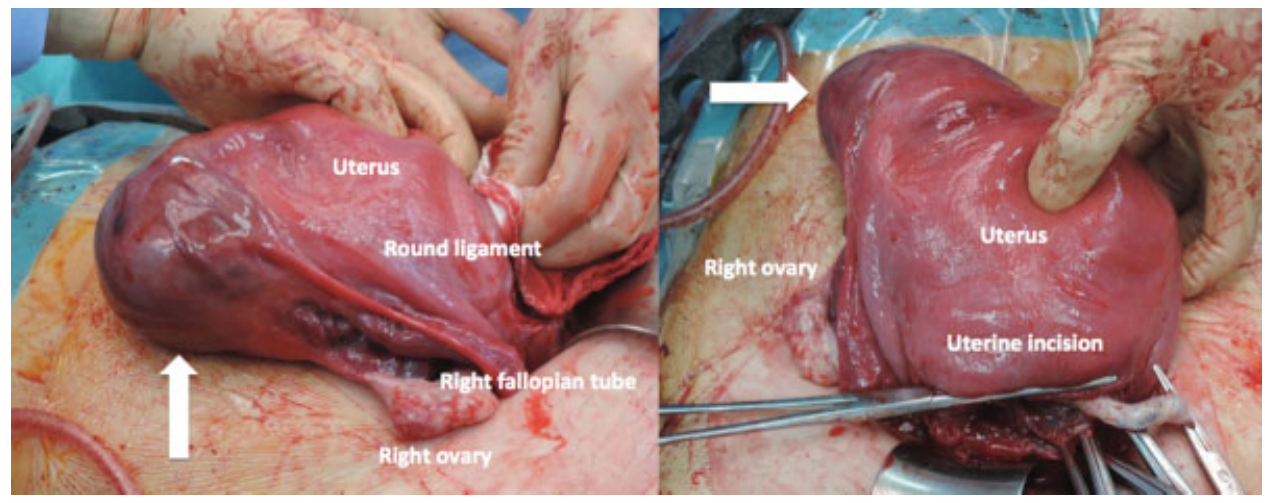

Fig. 1 The uterine fundus appeared intact, with an asymmetric bulge in the interstitial part of the right fallopian tube. The placenta was found to have implanted within the swelling (arrows).

right side was found to be enlarged with a discolored cystic swelling, through which placental tissue was visible (-Fig. 1). Although the patient received intravenous oxytocin, there was no evidence of placental separation even after $30 \mathrm{mi}-$ nutes. On the basis of these abnormal findings, a diagnosis of interstitial pregnancy and placenta accreta was clinically established. The patient was hemodynamically stable, and no blood transfusion was required. Therefore, we decided to complete surgery without removal of the placenta and waited until the placenta spontaneously delivered. Before the uterine incision was closed, we cut the umbilical cord short and ligated its edge with absorbable suture. A magnetic resonance imaging (MRI) examination during the postoperative period revealed a lateral myometrial margin that was less than $5 \mathrm{~mm}$ in thickness, lending credence to a diagnosis of interstitial pregnancy (-Fig. 2). On postoperative day (POD) 6 , the

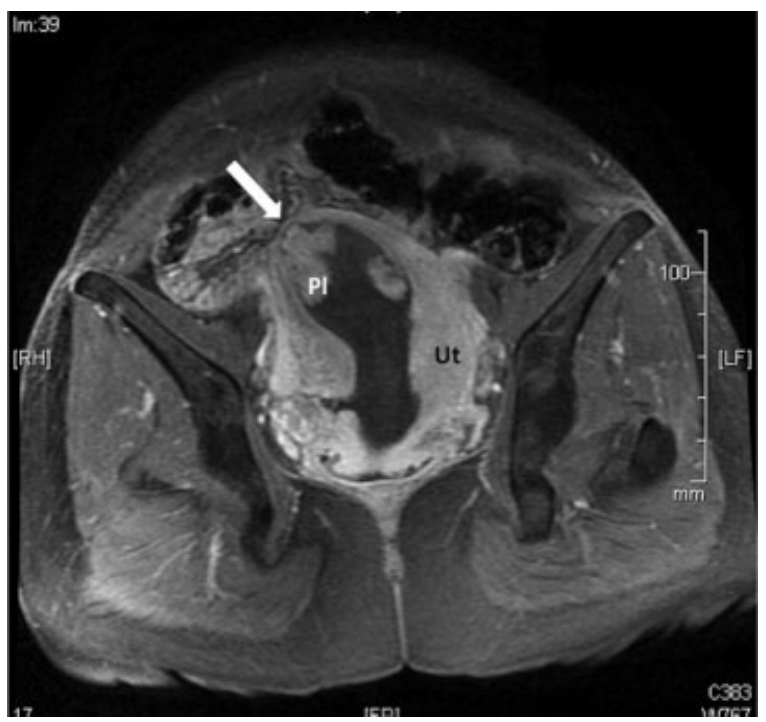

Fig. 2 An axial T1-weighted postcontrast image demonstrating a lateral myometrial margin $2 \mathrm{~mm}$ in thickness (arrow). Ut, uterus; PI, placenta. patient developed a persistent high fever over $38.0^{\circ} \mathrm{C}$. At this point, we collected blood cultures and started intravenous antibiotic therapy under the suspicion of intrauterine infection. On POD 8, the placenta was spontaneously removed without significant ongoing bleeding ( - Fig. 3). The patient's temperature normalized on POD 9. Her blood cultures were negative. The pathologic examination showed massive perivillous fibrin deposition (MPFD) (-Fig. 4). She was discharged on POD 13 and was doing excellently during the postoperative follow-up.

\section{Discussion}

Although interstitial pregnancies are frequently confused with angular pregnancies or cornual pregnancies, these are separate entities. Angular pregnancy is anatomically distinguished from an interstitial pregnancy by its position in relation to the round ligament. It refers to a viable intrauterine pregnancy that is implanted in one of the lateral angles of the uterine cavity, medial to the uterotubal junction. The lateral uterine enlargement of an angular pregnancy displaces the round ligament reflection upward and outward. In contrast, the swelling of an interstitial pregnancy is lateral to the round ligament. ${ }^{2}$ Cornual pregnancy refers to a pregnancy in a horn of a bicornuate uterus or in a lateral half of a septate/ subseptate uterus. ${ }^{2}$ Interstitial pregnancy refers to implantation of the embryo in the intramural portion of the fallopian tube covered by myometrium. Although histopathological confirmation is not provided in our case, a diagnosis of an interstitial pregnancy can be established according to the correlation of its position with the round ligament. ${ }^{2}$ Other authors propose that a thin layer of myometrium measuring less than $5 \mathrm{~mm}$ in thickness is suggestive of diagnosis of an interstitial pregnancy.,4 - Fig. 2 shows lateral myometrial margin $2 \mathrm{~mm}$ in thickness, and the MRI findings helped to confirm an interstitial pregnancy.

An interstitial pregnancy with live birth is extremely rare. English-language articles on PubMed published by June 30, 2013 were searched using the key word, "interstitial pregnancy." Only 10 cases of interstitial pregnancy with a viable 


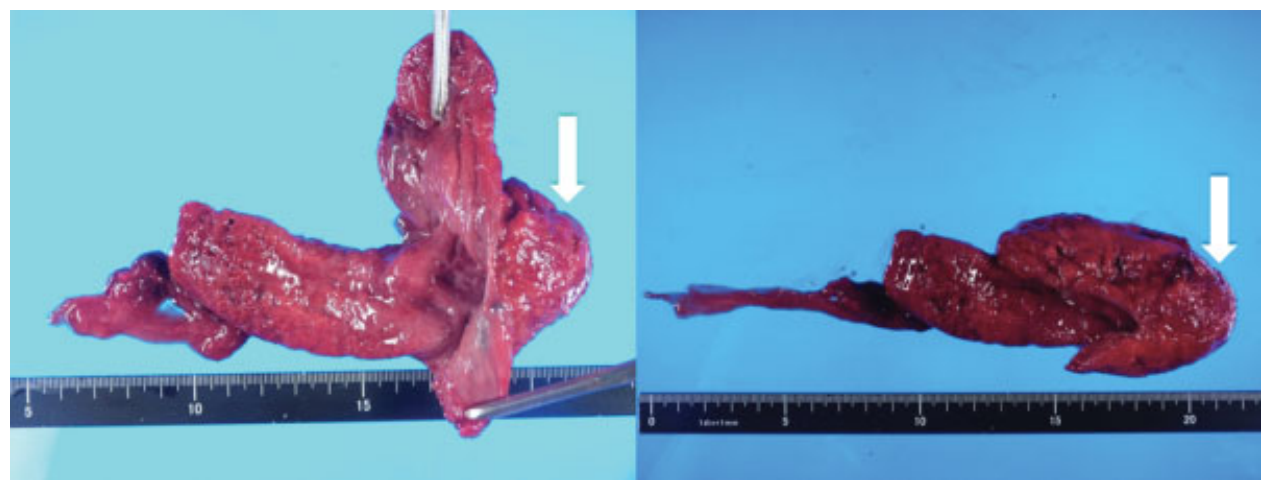

Fig. 3 The eccentric appearance of the placenta. The arrows point to the region that was attached to the interstitial portion of the right fallopian tube.

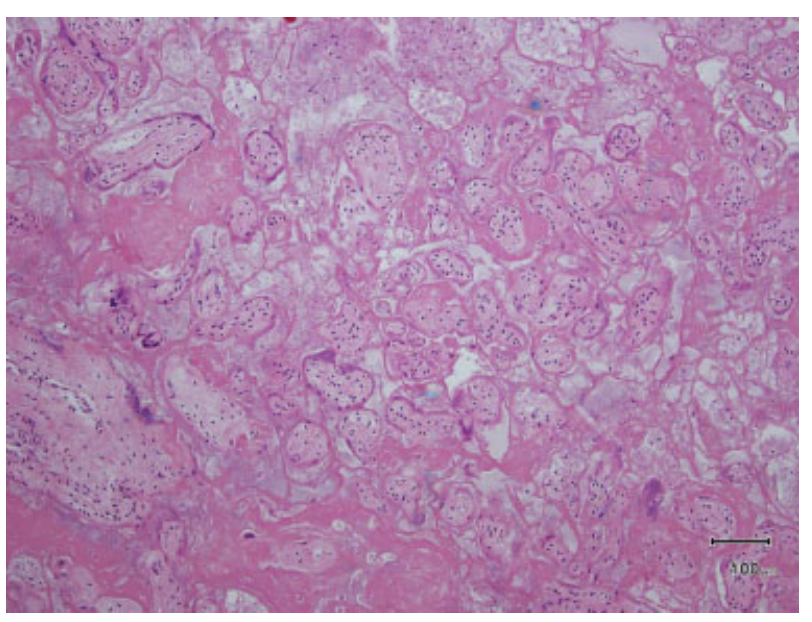

Fig. 4 Microscopic section of placenta. Note the loss of normal villous architecture and an encasement of villi in fibrinoid material. (Hematoxylin and eosin stain). infant have been reported previously. ${ }^{5-14}$ We were able to obtain detailed information for these patients, as shown in -Table 1. All patients underwent cesarean section for obstetrical indications, including uterine rupture in 4 of the 10 patients (40\%), $5,7,8,10$ malpresentation in 3, 6,11,12 and previous cesarean section in 2 patients. ${ }^{9,14}$ A prenatal diagnosis was established in one patient, ${ }^{13}$ and an elective cesarean section was performed. There has been no case of vaginal delivery in a patient with interstitial pregnancy diagnosed in the antenatal period. Expectant management is not advisable when a diagnosis of interstitial pregnancy is established at an early gestational age.

The placenta was markedly adherent to the uterus in 5 of the 10 cases $(50 \%), 5,7,9,11,13$ which clinically suggests the presence of placenta accreta. Four of the five cases $6,7,9,13$ were treated with hysterectomy and one was treated with intramuscular methotrexate injection. ${ }^{11}$ In our case, we chose expectant management, because there was no evidence of

Table 1 Characteristics of the 11 patients with interstitial pregnancy resulting in a viable infant

\begin{tabular}{|c|c|c|c|c|c|c|c|c|}
\hline $\begin{array}{l}\text { Reference } \\
\text { No. }\end{array}$ & $\begin{array}{l}\text { Reported } \\
\text { year }\end{array}$ & $\begin{array}{l}\text { Maternal } \\
\text { age }(y)\end{array}$ & $\begin{array}{l}\text { Previous } \\
\text { surgery }\end{array}$ & $\begin{array}{l}\text { Gestational } \\
\text { age (wks) }\end{array}$ & $\begin{array}{l}\text { Uterine } \\
\text { rupture }\end{array}$ & Mode of delivery & $\begin{array}{l}\text { Birth } \\
\text { weight }(\mathrm{g})\end{array}$ & Type of treatment \\
\hline 5 & 1988 & 29 & Myomectomy & 38 & Yes & Cesarean delivery & 3,010 & $\begin{array}{l}\text { Subtotal hysterectomy, } \\
\text { Salpingo-oophorectomy }\end{array}$ \\
\hline 6 & 1989 & 34 & - & 39 & No & Cesarean delivery & 3,110 & Supracervical hysterectomy \\
\hline 7 & 1997 & - & Myomectomy & 33 & Yes & Cesarean delivery & 2,100 & Subtotal hysterectomy \\
\hline 8 & 1997 & 24 & - & $\begin{array}{l}30 \\
\text { (Triplet } \\
\text { pregnancy) }\end{array}$ & Yes & Cesarean delivery & $\begin{array}{l}1,000 \\
1,140 \\
1,000\end{array}$ & Salpingectomy \\
\hline 9 & 1998 & 31 & $\begin{array}{l}\text { Cesarean } \\
\text { delivery }\end{array}$ & 37 & No & Cesarean delivery & 2,786 & Supracervical hysterectomy \\
\hline 10 & 1999 & 26 & - & 30 & Yes & Cesarean delivery & 1,682 & Cornual resection, salpingectomy \\
\hline 11 & 2007 & 25 & - & 38 & No & Cesarean delivery & - & Methotrexate \\
\hline 12 & 2010 & 36 & - & 39 & No & Cesarean delivery & 2,800 & $\begin{array}{l}\text { Supracervical hysterectomy, } \\
\text { Salpingo-oophorectomy }\end{array}$ \\
\hline 13 & 2012 & 30 & - & 28 & No & Cesarean delivery & 1,000 & Hysterectomy \\
\hline 14 & 2013 & 27 & $\begin{array}{l}\text { Cesarean } \\
\text { delivery }\end{array}$ & 32 & No & Cesarean delivery & 1,430 & Cornual resection \\
\hline Our case & 2013 & 35 & - & 32 & No & Cesarean delivery & 1,038 & Expectant management \\
\hline
\end{tabular}


ongoing bleeding during cesarean section. Although hysterectomy is a definitive therapy for placenta accreta, conservative management may be applied for patients who desire future fertility. According to the previously published literature evaluating expectant management of invasive placentation, the maternal mortality rate was reported to be $0.3 \%$ and a delayed hysterectomy occurred in $19 \%$ of cases. ${ }^{15}$ The median interval from delivery to delayed hysterectomy was 22 days, and the major causes of delayed hysterectomy included secondary postpartum hemorrhage, sepsis or both $(72.2 \%) .{ }^{16}$ In selected cases, especially when the patient is hemodynamically stable and there is no evidence of sepsis, it may be reasonable to wait for the spontaneous delivery of the placenta.

FGR was observed in 3 of the 10 cases (30\%). ${ }^{8,13,14}$ We hypothesize that the placental abnormalities in patients with interstitial pregnancy may be associated with FGR, and propose a possible explanation for the relationship between interstitial pregnancy and FGR. The eccentric position of the gestational sac and abnormal placentation may cause uteroplacental insufficiency, potentially leading to FGR. In addition, our case showed MPFD. MPFD is characterized by extensive deposition of fibrinoid material in the intervillous space and associated with hypoplasia and sclerosis of the engulfed villi. It is associated with serious complications of pregnancy including recurrent spontaneous abortion, FGR, and fetal demise. ${ }^{17}$ Some authors propose that an imbalance of angiogenic/antiangiogenic factors may play a role in the genesis of MPFD. ${ }^{18}$ Others suggest that it may reflect maternal antifetal rejection. ${ }^{19}$ However, the precise mechanisms leading to MPFD are not well defined.

In conclusion, if interstitial pregnancies are not diagnosed at an early gestational age, it can result in a viable fetus, but such pregnancies are associated with FGR or placenta accreta. When physicians encounter such rare circumstances, a wellorganized multiteam approach, continuous monitoring of the mother and the fetus, and careful discussion with the patient about the risks are necessary. Conservative management should only be considered in the case of a late diagnosis and in the absence of maternal and fetal compromise.

Conflict of Interest

The authors declare no conflict of interest.

\section{References}

1 Cunningham FG, Leveno KJ, Bloom SL, Hauth JC, Rouse DJ, Spong CY. Ectopic Pregnancy. In: Cunningham FG, Leveno KJ, Bloom SL,
Hauth JC, Rouse DJ, Spong CY, eds. Williams Obstetrics, 23rd ed. New York, NY: McGraw-Hill; 2010:238-256

2 Jansen RP, Elliott PM. Angular intrauterine pregnancy. Obstet Gynecol 1981;58(2):167-175

3 Lin EP, Bhatt S, Dogra VS. Diagnostic clues to ectopic pregnancy. Radiographics 2008;28(6):1661-1671

4 Rheinboldt M, Ibrahim S. Atypical presentation of a large interstitial pregnancy. Emerg Radiol 2013;20(3):251-254

5 Rosenzweig BA, Rotmensch S, Ressetar A. Term interstitial pregnancy resulting in a live infant. Obstet Gynecol 1988;72(3 Pt 2): 491-493

6 Bond AL, Grifo JA, Chervenak FA, Kramer EE, Harris MA. Term interstitial pregnancy with uterine torsion: sonographic, pathologic, and clinical findings. Obstet Gynecol 1989;73(5 Pt 2): 857-859

7 Ugwumadu AH, Hamid R, Ross LD. Live infant salvaged from a ruptured cornual (interstitial) pregnancy at 33-weeks gestation. Int J Gynaecol Obstet 1997;58(2):247-249

8 Luckas MJ, Fishwick K, Martin-Hierro M, Shaw GC, Walkinshaw SA. Survival of intrauterine twins and an interstitial singleton fetus from a heterotopic in vitro fertilisation-embryo transfer pregnancy. Br J Obstet Gynaecol 1997;104(6):751-752

9 Nishikawa A, Tanaka S, Kudo R. Full-term interstitial pregnancy with live birth. Int J Gynaecol Obstet 1998;63(1):57-58

10 Idama TO, Tuck CS, Ivory C, Ellerington MC, Travis S. Survival of cornual (interstitial) pregnancy. Eur J Obstet Gynecol Reprod Biol 1999;84(1):103-105

$11 \mathrm{Ng}$ PH, NorAzlin MI, Nasri NI. Term interstitial pregnancy with uterine conservation. Int J Gynaecol Obstet 2007;99(3):251

12 Milićević S, Jovanović D, Vilendecić Z, Ljubić A, Bozanović T, Niketić L. Full-term interstitial retroperitoneal pregnancy with delivery of a healthy infant. J Obstet Gynaecol Res 2010;36(4): 869-871

13 Scarella A, Marquez R, Schilling H, Palomino A. Antenatal diagnosis of a third trimester interstitial pregnancy: a case report. J Obstet Gynaecol Res 2012;38(3):570-573

14 Hill AJ, Van Winden KR, Cook CR. A true cornual (interstitial) pregnancy resulting in a viable fetus. Obstet Gynecol 2013;121(2 Pt 2, Suppl 1):427-430

15 Steins Bisschop CN, Schaap TP, Vogelvang TE, Scholten PC. Invasive placentation and uterus preserving treatment modalities: a systematic review. Arch Gynecol Obstet 2011;284(2):491-502

16 Sentilhes L, Ambroselli C, Kayem G, et al. Maternal outcome after conservative treatment of placenta accreta. Obstet Gynecol 2010; 115(3):526-534

17 Katzman PJ, Genest DR. Maternal floor infarction and massive perivillous fibrin deposition: histological definitions, association with intrauterine fetal growth restriction, and risk of recurrence. Pediatr Dev Pathol 2002;5(2):159-164

18 Whitten AE, Romero R, Korzeniewski SJ, et al. Evidence of an imbalance of angiogenic/antiangiogenic factors in massive perivillous fibrin deposition (maternal floor infarction): a placental lesion associated with recurrent miscarriage and fetal death. Am J Obstet Gynecol 2013;208(4):310.e1-310.e11

19 Romero R, Whitten A, Korzeniewski SJ, et al. Maternal floor infarction/ massive perivillous fibrin deposition: a manifestation of maternal antifetal rejection? Am J Reprod Immunol 2013;70(4):285-298 